\title{
A pesquisa psicanalítica na universidade como oportunidade de debate dos fundamentos psicanalíticos
}

\author{
Maíra Marchi Gomes \\ Fernando Aguiar
}

\section{RESUMO}

Este artigo discute os termos em que se dá a pesquisa psicanalítica na universidade, a partir de conceitos fundamentais da psicanálise. Começa situando historicamente a psicanálise no campo das ciências, localizando-a atualmente no campo das ciências humanas, e definindo a pesquisa psicanalítica pelo tratamento clínico dos dados, particularmente no ato da escrita. Funda-se tal argumento a partir das pesquisas sobre a interface sujeito-sociedade, porque elas explicitam alguns fundamentos psicanalíticos: o inconsciente (objeto da pesquisa psicanalítica) não está apenas na prática clínica; o objeto é construído a partir da relação estabelecida pelo pesquisador; e a interpretação é o método de acesso ao objeto. Conclui-se que a pesquisa psicanalítica na universidade, além de possível, possibilita legitimar alguns dos principais conceitos psicanalíticos.

Palavras-chave: pesquisa; psicanálise; universidade.

\section{ABSTRACT}

The psychoanalytic research at the university as a debate opportunity of psychoanalytic fundamentals

This article discusses the conditions under which the psychoanalytic research at the university is developed, based onfundamental concepts of psychoanalysis. At the beginning of this article, psychoanalysis is historically located in science, specifically in the field of human sciences, and defines the psychoanalytic research as the clinical treatment of data, particularly in the act of writing. That argument is based on the research on the subject-society interface, because they explain some psychoanalytic fundamentals: the unconscious (the psychoanalytic research object) is not only in clinical practice; the object is constructed from the relationship established by the researcher; and interpretation is the method of access to the object. We conclude that psychoanalytic research at the university is not only possible but also allows to legitimize some of the key concepts psychoanalytic.

Keywords: research; psychoanalysis; university

Um dos motivos pelos quais é pertinente discutir onde se localiza a psicanálise no campo das ciências é dado de saída pelo fato mesmo de se realizar pesquisas em psicanálise na universidade. Aliás, Garcia-Roza (1994) justifica a significativa inserção da psicanálise na universidade mencionando "a incidência inevitável e indispensável do pensamento psicanalítico em qualquer questão referente ao psiquismo, e ainda mais amplamente em qualquer questão referente às formas de vida e da Cultura Contemporânea" (p. 9).

Porém, o fundador da psicanálise chega a afirmar que a universidade poderia se beneficiar da psicanálise, mas não a psicanálise da universidade, uma vez que sua disciplina, que não nasceu na academia, já dispunha por conta própria de seus lugares de formação (Freud, 1919/1996). Quase um século depois, talvez seja possível pensar que, nas relações entre psicanálise e universidade, em particular no âmbito da pesquisa, ambas estão interessadas uma na outra. Daí a relevância de discutir em que termos pode-se dar este diálogo, verificando

\section{Sobre os Autores \\ M.M.G. \\ orcid.org/0000-0002-9409-8488 \\ Universidade Federal de Santa \\ Catarina (UFSC) - Florianópolis \\ $\mathrm{SC}$ \\ mairamarchi@gmail.com \\ F.A. \\ orcid.org/0000-0003-4473-480X Universidade Federal de Santa \\ Catarina (UFSC) - Florianópolis, $\mathrm{SC}$ \\ fernando.aguiar@ufsc.br}

\section{Direitos Autorais}

Este é um artigo de acesso aberto e pode ser reproduzido livremente, distribuído,

transmitido ou modificado, por qualquer pessoa desde que usado sem fins comerciais. 0 trabalho é disponibilizado sob a licença Creative Commons CCBY-NC. 


\section{H. INTERACÃO EM 2. PSICOLOGIA}

sua pertinência para a psicanálise e, mais especificamente, como sua atividade de pesquisa explicita algumas de suas concepções fundamentais.

Outro motivo, quase um corolário do anterior, diz respeito à oportunidade de relevar e debater críticas dirigidas à invenção freudiana. Acusam-na de não ser uma ciência, afırmam a baixa eficácia de seu tratamento e a fragilidade da teoria (por reconhecer e admitir a influência da subjetividade do profissional), a não comprovação de seus pressupostos e a ausência de verificação de suas hipóteses, que, no entanto, "dão sempre razão a quem as enuncia" (Mezan, 2007, p. 320). Assim, este artigo retoma à discussão que envolve a caracterização da psicanálise como ciência, para refletir em diversas frentes sobre o tipo de ciência que melhor convém à sua práxis, em particular no que se refere à pesquisa desenvolvida em interfaces com outros campos e áreas do saber universitário.

Isto tem importância para os psicanalistas que transitam no âmbito universitário, dada a óbvia exigência de que demonstrem como a psicanálise atua, que resultados produz e a quem é indicada. Como relata Garcia-Roza (1994), a união do psicanalítico com o acadêmico é via de regra questionada pelos supostos representantes do saber acadêmico (especialmente pelos que avaliam e liberam recursos), ao mesmo tempo pelos que se apresentam como donos do exercício da formação e transmissão da psicanálise. 0 autor também inclui, na análise da pouca legitimidade atribuída à psicanálise, o fato de a pesquisa e o ensino em psicanálise habitualmente serem realizados em institutos de psicologia ou em outras faculdades, daí correndo o risco de perder sua especificidade por meio de sua apropriação por outros saberes.

Garcia-Roza (1994) exemplifica os efeitos desta situação com as comuns críticas sofridas pelo pesquisador acadêmico em psicanálise que trabalha ao lado de pesquisadores em psicologia. Por parte dos psicólogos, por defender a irredutibilidade do discurso psicanalítico, e, por parte dos psicanalistas, por submeter o discurso psicanalítico às regras do discurso universitário. Birman (1994) lembra, nesta direção, que desde as décadas de 30 e 40 o estatuto científico, teórico e de pesquisa em psicanálise foi ambíguo no campo da pesquisa em psicologia. A explicação seria a concepção neo-positivista e empirista que sempre foi e é o modelo epistemológico dominante na psicologia mundial, e especialmente no Brasil.

Herrmann (1994) é um autor que acompanha as reflexões dos autores acima citados. Para ele, há uma tendência epistemológica na crítica das ciências às pesquisas acadêmicas: a filtragem do conhecimento para verificar se algo é ou não verdadeiro. Esta lógica restritiva manifestar-se- ia, por exemplo, na preocupação em pesquisas psicanalíticas em dizer que, apesar de ser psicanálise, são verdadeiras as postulações em questão. 0 autor chega a ser radical, afirmando que "a psicanálise é suficientemente forte enquanto método para obrigar a universidade e o conjunto das ciências, especialmente as ciências humanas, a se definirem e a redefinirem a sua forma de entender a própria epistemologia" (Herrmann, 1994, p. 54).

Um caminho interessante para problematizar a questão sobre similaridades e diferenças na pesquisa da prática clínica e no discurso conceitual é levantado por Garcia-Roza (1994). Ele alerta que a principal questão não é uma suposta oposição entre discurso conceitual e psicanalítico, mas entre duas concepções de conceito: 1) entidade abstrata, universal formal; e 2) singularidade, que responde a verdadeiros problemas. Se aderimos à primeira definição, o pesquisador é aplicador de métodos científicos e suas conclusões são confirmações vazias de sentido. Se concordamos com a segunda, o pesquisador é alguém ávido por decifrar os segredos da sabedoria.

Talvez seja por acompanhar esta "solução" para a questão que Garcia e Silva (1994) compreendem que o que define a pesquisa psicanalítica é a interpretação das forças subjacentes a uma experiência humana ou seu produto. Em outros termos, a busca da determinação desconhecida, ao invés da representação convencional e lógica, passível de mensuração e demonstração. Couto (1996) explica que o empreendimento de Freud não foi o da chamada "ciência normal", que visa validação, confirmação, esclarecimento de sentido ou refutação de proposições estabelecidas. Fazendo uma revolução científica, o pai da psicanálise não aceitou as teorias vigentes, o que seria um pressuposto caso questionasse e buscasse explicações por outro ponto de vista. Da mesma forma, não testou uma conjectura específica de certa teoria, mas ao estabelecer um novo objeto de estudo, o inconsciente, rompeu com o cotidiano das disciplinas.

De fato, não só aos psicanalistas que dialogam com o espaço universitário, mas a qualquer pesquisador que utilize o saber psicanalítico (psicanalista ou não) se dirigem questionamentos desta ordem. Logo, a todos aqueles que operam com a psicanálise parece fundamental revisitar questões epistemológicas a partir da psicanálise.

\section{DAS PRIMEIRAS DISTINÇÕES}

Referindo-se aos textos em que Freud aborda o caráter de sua invenção, Mezan (2007) atém-se a "Sobre uma Weltanschauung", das Novas conferências de introdução à psicanálise, de 1932 (até por ser uma obra mais tardia e, então, supostamente mais elaborada e definitiva). Recorta 


\section{N"INTERACÃO EM ET PSICOLOGIA}

dali a concepção psicanalítica do que seja uma ciência: em linhas gerais, uso da razão e revisão de teoria; oposição à revelação, intuição, adivinhação, religião e filosofia; limitação à esfera do observável, ou pelo menos ao que pode ser inferido como fundamento do observável (força, átomo, inconsciente); um método de investigação (observação, hipóteses, prova lógica, matemática ou experimental, etc.). Em outros termos, coesão interna, comunicabilidade, verificabilidade e cumulatividade são características levadas em conta nas formulações científicas que tampouco estão ausentes das formulações freudianas.

Em outro artigo, Mezan (2007) retoma os argumentos que atribuem estatuto de ciência aos saberes da humanidade, que partem curiosamente da aproximação, reclamada por Freud, entre a psicanálise e as ciências naturais (cujo modelo é para ele o da física), inclusive, tomando delas emprestado alguns termos para sua construção teórica. Mas é da teoria darwiniana que a psicanálise mais se aproximaria, neste sentido de que, tal como a evolução mediante a seleção natural, ela não pode ser provada, nos moldes da física e da química, através de evidência empírica imediata. Sim, como a seleção natural, fundamenta-se em inferências e conjeturas. Por sua vez, as forças psíquicas conforme propostas por Freud também não são mensuráveis e nem passíveis de matematização, daí seu fundador, ao formular conceitos e argumentar teoricamente, ter recorrido a metáforas e analogias muitas vezes resgatadas, para além das ciências físicas e naturais, da grande literatura, da mitologia grega e das produções culturais de um modo geral.

Para se compreender esta apropriação que o fundador da psicanálise faz das ciências naturais e das ciências do espírito, é necessário considerar que, ao vincular sua invenção ao modelo das ciências naturais, o que Freud pretende é muito menos atribuir sentido às formações do inconsciente do que explicar suas causas e condições de formação - tal como no sonho, no qual a interpretação é menos importante que sua elaboração onírica, cujos principais mecanismos são chamados de condensação e deslocamento. Tanto na psicanálise aplicada à clínica como às questões históricas e culturais, o que vemos é sua "procura sistemática das causas e disposição para retificar incessantemente a teoria à luz dos 'fatores novos e inesperados"' (Mezan, 2007, p. 336). A originalidade de Freud está precisamente em operar sobre a especificidade individual do objeto (próprio de pesquisas sobre objetos históricos ou culturais) com recursos da explicação (comumente usados ao se pesquisar objetos naturais), e não da compreensão (inerente às pesquisas sobre objetos históricos ou culturais). Sua recusa em adotar o método compreensivo deveu-se a um posicionamento contrário a opções metafísicas e às interferências do pesquisador eivadas de juízos de valor.

$\mathrm{Na}$ atualidade, o estatuto de ciência representado pela psicanálise é situado por Mezan (2007) no campo das ciências humanas, pois, mesmo considerando que interpretar é encontrar o sentido e a causa, a concepção de "causa" que temos hoje aproxima a psicanálise das ciências humanas da atualidade. 0 fundamento desta concepção é o de que, na avaliação dos motivos envolvidos nos sintomas ou estados patológicos, aumentou significativamente o peso causal atribuído pelas novas formulações psicanalíticas às diversas relações estabelecidas pelo sujeito. Legitimar a psicanálise como ciência humana assenta-se na razão de que as relações interpessoais são mais inerentes ao campo do humano que do natural. Mais ainda: seria precisamente no campo do humano que a concepção de causalidade atinge sua maior complexidade, tal como operacionalizada pela psicanálise: uma causalidade múltipla.

A concepção de causalidade, que hoje identifica a psicanálise como uma ciência humana, caracteriza inclusive seu método de investigação como dispositivo, seja de tratamento, seja de pesquisa, já que em ambos os casos a "escuta" permanece a mesma e há uma busca de elucidação das causas (nos termos acima apresentados). Tanto escutando seu paciente como escrevendo textos, o analista busca uma elucidação, ainda que apenas na primeira dessas atividades esta elucidação possa trazer, por acréscimo, alguma transformação.

Nesta direção, pode-se lembrar do caso Dora (Freud, 1905/2016), emblemático do início da psicanálise. Desenvolvido ao longo de apenas três meses, de maneira intensa, uma de suas grandes contribuições foi revelar o efeito da interpretação. Freud surpreendeu-se com o desaparecimento dos sintomas apresentados pela paciente tão logo Ihe apresentava seu construto do significado de seu quadro psicopatológico. Evidentemente que, posteriormente, a psicanálise discutiu outros aspectos sobre a remissão sintomática; por exemplo, de que não basta tratar o sintoma se o conflito subjacente não for de fato analisado, posto que tal conflito se manifestaria por outras vias sintomáticas. De qualquer forma, o que aqui se ressalta é a importância de se focar a causa dos sintomas e não se restringir a sua superfície. Ou, focar o que está latente, e não o que é manifesto.

Além da concepção de causalidade, há outro aspecto que faz com que a psicanálise hoje seja entendida como ciência humana: os objetos das ciências humanas exigem metodologias diferentes daquelas hoje utilizadas pelas ciências naturais. 0 método experimental não pode ser aplicado quando o objeto é imaterial, único, excessivamente 
grande ou pertencente ao passado. A propósito, somos lembrados, ainda por Mezan (2007), de que o modelo de ciência biológica da época de Darwin se adequaria hoje às ciências humanas, que utilizam métodos que ultrapassam a compreensão, e cujos objetos seriam mais próximos do que antes se entendia como "objetos da natureza" do que dos "objetos do espírito".

Trata-se de reconhecer que as teorias de Freud, assim como as de Darwin, não podem comprovar a veracidade das inferências construídas a partir dos dados por meio de evidências imediatas e conclusivas. A "veracidade" estaria muito mais fundamentada na consistência interna do argumento, na simplicidade e plausibilidade da hipótese central, e na dimensão do poder explicativo da teoria tomada em seu conjunto. Ora, na concepção contemporânea de ciências naturais e humanas, "nada vemos de estranho em atribuir leis e causas ao universo da cultura, e certamente já não entendemos por 'significação' de um produto humano a expressão de um princípio que só o método compreensivo poderia alcançar" (Mezan, 2007, p. 352).

Evidentemente que, em relação às ciências biológicas, as ciências humanas ainda guardam outras especificidades. Por exemplo, a indução e a dedução utilizam procedimentos diferentes dos das ciências do inanimado. "Há poucas generalizações indutivas; predomina o estudo de casos exemplares" (Mezan, 2007, pp. 347-348), e as deduções dependem das premissas entre si e destas com a conclusão.

Por fim, é necessário demarcar outra das características das ciências humanas: a impossibilidade de padronização de procedimentos. Considerando haver objetos que em si impossibilitam as formas de aproximação típicas das ciências naturais, cada disciplina humana definiria a legitimidade de problemas, a pertinência dos procedimentos, os critérios para estabelecimento e confirmação de hipóteses, etc. 0 progresso do conhecimento nessas ciências se evidenciaria pelo estabelecimento de um núcleo sólido de informações coerentes.

Eis o que em suma traz aceitabilidade a uma teoria: consistência interna, compatibilidade com os princípios gerais do campo epistemológico da disciplina e seu valor heurístico para lidar com novas descobertas, por meio de modificações ou substituições.

Em poucas palavras, se hoje o perfil epistemológico da psicanálise aproxima-se em vários aspectos ao de disciplinas humanas, se o objeto da psicanálise é do campo do humano e se seus métodos assemelham-se aos das ciências humanas, por que então - parafraseando também neste contexto a velha história judia recuperada pelo próprio Mezan (1998) em sua argumentação sobre a "identificação projetiva" - ela não seria uma ciência humana?

\section{TIPOS DE PESQUISA PSICANALITICA?}

Se até aqui discorremos sobre pesquisas psicanalíticas de maneira genérica, cabe minimamente apresentar o amplo universo de tais pesquisas. Parece haver, na universidade, uma predominância de pesquisas ditas de psicanálise aplicada - no sentido, que remonta aos primeiros psicanalistas, de mostrar que as mesmas forças que "animam toda e qualquer produção mental, individual ou coletiva, podem ser detectadas não apenas na situação clínica, mas ainda nas produções secundarizadas" (Mezan, 1994, p. 67) - e histórico-conceituais, que se caracterizam pelo maior relevo dado à teoria psicanalítica (Mezan, 1994).

Em próxima concordância, Dreher (2008, p. 132) cita como áreas temáticas de pesquisa psicanalítica a "pesquisa em psicoterapia com análise de processos e resultados, pesquisa de desenvolvimento e pesquisa histórica ou, por exemplo, pesquisa conceitual". Observa ainda a diversidade das matérias de estudo, utilizando diferentes paradigmas em pesquisa, além de diferentes propostas em termos de organização do campo de pesquisa psicanalítica. Tais propostas divergiriam quanto às classificações e divisões.

Silva, Yazigi e Fiore (2008, p. 153), por sua vez, relacionam como modelos de pesquisa psicanalítica a empírica, a teórica ou conceitual e a clínica, observando que os trabalhos acadêmicos, via de regra, não são psicanálise propriamente dita, no sentido de aplicação do método psicanalítico na clínica, mas versam "sobre" Psicanálise. Em seus termos: "este modelo foi fortemente influenciado pela Psicanálise francesa como forma de inserção na Universidade .... A pesquisa clínica, instrumento preferencial de Freud, desenvolveu-se nas Sociedades de Psicanálise".

A própria definição do que seja pesquisa em psicanálise, para além de suas classificações e divisões, não encontra consenso. "Às vezes ela é entendida de forma solta, como uma metáfora; outras vezes, como um programa metodologicamente sofisticado - e cada caso abriga uma série de atividades sob sua marca" (Dreher, 2008, p. 139). Diferentes concepções do que seja pesquisa em psicanálise acarreta, para a autora, metodologias que dificilmente são conciliadas. Especificamente, faz com que haja quem se dirija a casos individuais e únicos, e quem se oriente para a coleta de amostras e leis universais.

Esta mesma divergência quanto ao entendimento do que seja pesquisa em psicanálise se revela em outro aspecto: há psicanalistas que, seguindo uma convicção analítica clássica, compreendem sua prática como uma pesquisa (do inconsciente dos pacientes e dos próprios analistas). Por outro lado, há quem, considerando a compreensão moderna do que seja ciência (com sua concepção de pesquisa e 


\section{- INTERACÃO EM ET PSICOLOGIA}

critérios de pesquisa científica), pensa que não se pode chamar de pesquisa, por exemplo, os estudos de caso. As críticas dirigem-se ao fato de um único pesquisador gerar hipóteses, colher e interpretar os dados. A estruturação individual de todo o processo de pesquisa "não se coaduna facilmente com as convicções provindas de um entendimento de pesquisa orientado por padrões de intersubjetividade" (Dreher, 2008, p. 139).

Dreher (2008) faz um interessante questionamento sobre a possibilidade de se avaliar as denominadas "pesquisas de conjunção" (conjunção entre tratamento e pesquisa, conforme Freud propôs) a partir dos entendimentos modernos empiricamente orientados sobre pesquisa1. Segundo a autora, o processo de pesquisa que obedece a tais ditames via de regra se encontra distante tanto da situação analítica como da experiência subjetiva direta. Isto porque os processos inconscientes só podem ser inferidos pela via de métodos hermenêuticos (não podendo ser apreendidos e medidos quantitativamente), e porque o analista ocupa um papel fundamental no processo de pesquisa. Apresenta o seguinte como conclusão:

Podem ser de interesse para nós não apenas a via de pesquisa genuinamente analítica, mas também a prática de pesquisa gerada, por exemplo, pelo empirismo e pelo cognitivismo, assim como, e sobretudo, pelas ciências hermenêuticas. No entanto, a importância da prática analítica nas várias áreas de pesquisa permanece inquestionável para a maioria de nós: a situação analítica, com sua ênfase na subjetividade, na interação, na experiência compartilhada e nos processos inconscientes, continua a ser o centro, a base empírica e também o lugar indispensável de justificação. Essa particularidade sem dúvida põe um freio na importação de outras tecnologias de pesquisa para a psicanálise (Dreher, 2008, p. 140).

Se a clínica parece ser o lugar por excelência onde se faz pesquisa psicanalítica, não se pode deixar de questionar se (e como) uma pesquisa desta natureza se daria em outros contextos. Afinal, lembra Herrmann (2004), não são apenas psicanalistas que realizam pesquisas psicanalíticas. Mais de dois terços do que o próprio Freud publicou não se tratava de descrições de análises. Para Herrmann, pesquisa psicanalítica não se dá apenas em consultórios, ainda que a maior parte sim. A pesquisa psicanalítica legitimar-se-ia na escrita. Em toda pesquisa científica há uma parcela de arte combinada, que, no caso da psicanálise, é a literatura. "Freud explorou com excelência essa combinação onde, enquanto ciência, a psicanálise é arte, mas sempre faz ciência, quando literatura" (Herrmann, 2004, p. 25).

Na mesma direção, propõe Bianco (2003) que o próprio objeto da psicanálise (o sujeito do inconsciente) impôs novas formas de investigação. O campo psicanalítico teria como maior especificidade o acréscimo, ao momento da experiência analítica (da clínica, da presença do analista e analisando), da escrita. Já para Herrmann (2004), podemos ir além desta fundamentação do caráter de pesquisa da escrita psicanalítica. Para ele, o relato de uma sessão, e inclusive de uma análise, não necessariamente permite uma tese acadêmica. Entretanto, a forma de trabalho clínico poderia resultar num método de investigação e cura aplicável não apenas à análise padrão, mas à clínica extensa e ao estudo clínico da psique cultural. Esta alternativa seria mais interessante que ignorar esta possibilidade de alcançar o sentido psíquico do mundo ou substituí-lo por pesquisas estatísticas ou comentários teóricos.

Podemos assim concluir que o que legitima a psicanálise como pesquisa não é a prática clínica, mas a escuta clínica. Uma escuta que, a propósito, dar-se-ia de maneira especial no momento da escrita. Esta concepção fica mais compreensível se considerarmos a proposta de Mezan (1994) de que o que define a psicanálise é uma combinação entre o processo primário e o secundário. Ela não se restringiria a uma catarse, justamente pela não predominância ininterrupta do processo primário; ao mesmo tempo, também não seria unicamente uma terapia de sugestão, intelectual, porque para isto o processo secundário precisaria predominar o tempo todo.

A psicanálise seria uma experiência, e não uma pesquisa. Ela só se tornaria pesquisa a posteriori, quando o analista reconstitui e pensa o que escutou e viveu enquanto escutava o paciente. Neste momento, o processo secundário passaria a reger o funcionamento psíquico do analista, que para conseguir escutar o analisando em sua livre associação, havia se deixado tomar predominantemente pelo processo primário da escuta flutuante. É só utilizando um trabalho de linguagem que se pode conceitualizar a experiência e, para este autor, este trabalho é essencialmente metafórico, dispondo de conceitos provindos da cultura do psicanalista e de sua experiência de vida. É dali que ele retiraria seu repertório de interpretações.

Por fim, cabe salientar que, ainda segundo Mezan (1994), há diferença entre o trabalho realizado pelo psicanalista em sua formação e aquele que ele pode fazer em uma pósgraduação. Na universidade a discussão do trabalho clínico não é comum, e predomina o processo secundário. Porém, para o autor, mesmo aí a experiência clínica é desejável, ainda que se precise refletir sobre o modo de se referir a ela, e sobre o grau de familiaridade que um universitário que pesquisa psicanálise precisaria ter com o processo clínico.

Parece, então, que o que assemelha o psicanalista em formação e o pesquisador em psicanálise é uma certa 


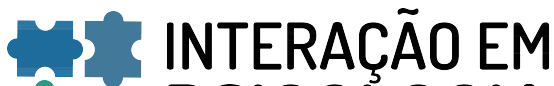 ET PSICOLOGIA}

modalidade de comunicação: a escrita. E, ainda, que este momento pode ser chamado de ato de pesquisa. Também se pode dizer que o diferencial entre essas duas maneiras de se aproximar da psicanálise parece ser que do psicanalista em formação exige-se uma experiência em psicanálise, mas do acadêmico deseja-se uma experiência.

\section{DO MAIS ESPECIFICO DAS PESQUISAS PSICANALITICAS}

No campo das pesquisas psicanalíticas, uma das melhores maneiras de evidenciar que a clínica psicanalítica não se dá apenas em consultório (já que é acima de tudo uma forma de escutar) talvez sejam as pesquisas que tratam da interface psique/sociedade. Sobre elas, é pertinente iniciar considerando que nas pesquisas psicanalíticas - em havendo pessoas entrevistadas (no caso da entrevista ser um procedimento metodológico para coleta de informações) seu objeto não se refere a pessoas (Mezan, 2002). As pessoas encarnam o suporte do objeto, sendo o meio pelo qual este objeto se presentifica para o analista.

Tal compreensão pode se sustentar no fato de que, para além do tratamento psicanalítico, o inconsciente também se apresenta em manifestações sociais e culturais (Rosa \& Domingues, 2010). Transcendendo qualquer discurso, a enunciação faz com que o sujeito recorte este discurso: em todo enunciado há uma enunciação, e é justamente o sujeito do inconsciente ali presente que torna possível a pesquisa psicanalítica de fenômenos sociais.

Poderíamos inclusive dizer que as pesquisas psicanalíticas na interface psique-sociedade permitem a explicitação da própria concepção de sujeito para a psicanálise: uma concepção não individualizante e que mesmo ao abordar temas não diretamente sociais considera aspectos exteriores ao sujeito. Lembrando a afirmação de Freud $(1921 / 2011)$ de que toda psicologia é social, a psicanálise posiciona-se contrariamente à concepção segundo a qual indivíduo e sociedade se influenciam mutuamente - porque seria justamente pressupor esta dissociação. 0 sujeito do inconsciente não é intrapsíquico e é "constituído a partir do desejo do outro, recriado a cada relação com o outro, e depende da modalidade de laço social" (Rosa \& Domingues, 2010, p. 183).

Esta concepção psicanalítica de sujeito a que é exemplarmente fiel às pesquisas sobre a interface psiquesociedade é, por sua vez, o que explica outra particularidade das pesquisas em psicanálise: não só reconhecer a influência do pesquisador, mas considerar fundamental sua problematização. O conceito de transferência faz com que o pesquisador em psicanálise seja parte dos "dados". Estamos tratando aqui especificamente da transferência como via de acesso ao seu objeto de estudo, ou seja, às produções do inconsciente. É a interação entre pesquisador e interlocutor, num processo de transferência, que constrói o campo de observações. Portanto, o dado não é buscado, observado ou revelado, mas construído. "Está em jogo a posição em relação ao interlocutor, os laços discursivos que se estabelecem de modo que as dimensões diante dos ideais e a imagem de si compareçam ao lado da implicação nas ações, nos excessos não reconhecidos" (Rosa e Domingues, 2010, p. 185).

Portanto, o método psicanalítico integra teoria, prática e pesquisa. A observação dos fenômenos é que produz o objeto de pesquisa, que não é dado a priori, mas produzido (construído) na e pela transferência. Indo do fenômeno ao conceito (e vice-versa), a metapsicologia psicanalítica fundamenta-se na escuta psicanalítica e não na interpretação a priori e mecanicamente derivada de uma teoria. 0 método psicanalítico não faz uma aplicação de teorias, mesmo reconhecendo que é o conhecimento prévio de uma teoria (neste caso, flutuante e não dirigida) que torna o pesquisador capaz de reconhecer certos dados.

No método de pesquisa psicanalítica, sendo o objeto produzido na e pela investigação, o desejo do investigador compõe a investigação. 0 campo da psicanálise é atravessado pelo seu próprio objeto (o inconsciente), "mediante sua personificação no sujeito que pensa e escreve" (Mezan,1993, p. 118). A pesquisa em psicanálise define-se pelo modo de formular as questões (que considera a subjetividade de quem pergunta), e não pelo tema e/ou lugar.

Este desejo do investigador presentifica-se na ação de interpretação, que é definidora da pesquisa em psicanálise. "A passagem inventada por Freud da ausculta para a escuta não representou uma mudança de instrumento de observação, mas, antes, uma mudança da postura de observação para a de interpretação, do visível para o audível, da constatação para a construção" (Kupfer \& Voltolini, 2005, p. 362). Como nos explicam Matos et al. (2008), o procedimento psicanalítico para pensar e tratar as questões do sujeito (aqui entendido como não sendo uma unidade, e afetado pelo inconsciente) não é o da compreensão nem o do esclarecimento. É a interpretação.

\section{PSICANÁLISE COMO MÉTODO DE INTERPRETAÇÃO}

A psicanálise é eminentemente um método interpretativo, e se diferencia por se assentar na livre associação do analisando, viabilizada pela transferência e pela escuta flutuante da parte do analista. 0 modelo em que se baseia o pesquisador psicanalítico é dado pelo analisando, no divã. 0 lugar da alteridade na pesquisa psicanalítica é ocupado tanto pelos dados de pesquisa (o que o analisando diz de seu 
sofrimento psíquico, inserido em uma situação de transferência), como por aqueles a quem se destina a pesquisa e a quem o autor reporta o testemunho de sua investigação - os leitores, também eles atingidos pelo fenômeno da transferência (Iribarry, 2003).

É possível inclusive pensar que, sendo a transferência o espaço onde se constroem os dados psicanalíticos, toda pesquisa psicanalítica é social. A pesquisa em psicanálise "parte do singular, tenta apreender as determinações desta singularidade (inclusive do sujeito que assim procede), e visa extrair dela a dimensão universal que, por sua própria natureza, ela contém" (Mezan,1993, p. 118, grifo nosso).

Pode-se argumentar que o reconhecimento da influência do pesquisador como coparticipante na construção dos dados não é uma particularidade psicanalítica, se levamos em conta a crítica que diversos campos do saber fazem ao paradigma de neutralidade da ciência moderna. No entanto, a novidade é que, com a psicanálise, o foco de pesquisa é precisamente tal influência. Não sem razão, a psicanálise constituiu-se, tantas vezes, em exemplo recorrente de uma forma de fazer ciência - da qual se é contra ou a favor, conforme o ponto de vista do epistemólogo em questão.

Em outras palavras: se o objeto de estudo é o que surge na relação entre pesquisador e pesquisado, mas se em várias orientações metodológicas o autor aparece também como participante fundamental, na pesquisa psicanalítica esta é sua condição e premissa básica da relação entre o mundo subjetivo do autor e o mundo objetivo da realidade investigada (Iribarry, 2003). Ao falarmos de realidade psíquica, expressão cara a Freud, as noções de subjetivo e objetivo relativizam-se.

\section{PSICANÁLISE E SUAS RELAÇÕES COM A MODERNIDADE}

Podemos agora melhor nos acercar de outra especificidade da pesquisa em psicanálise: o questionamento à concepção moderna segundo a qual o objeto de estudo existe previamente à situação de observação. Se esta é uma discussão fundamental às pesquisas na interface entre a psicanálise e os campos do saber fundados em paradigmas modernos, parece pertinente a toda pesquisa psicanalítica em universidade, haja vista ser este $\mathrm{o}$ ambiente onde mais se exige que as pesquisas obedeçam a tais paradigmas.

Ainda assim, deve-se reconhecer que é principalmente nas tentativas de diálogo com campos do saber fundados em paradigmas modernos que a disciplina freudiana encontra significativa resistência. Tratando das "miragens gêmeas do saber absoluto e intuição inefável” (Mezan, 1993, p. 118), há essa persistência na ciência moderna, como resquício essencialmente religioso, do ideal de saber absoluto, e repulsa ao que, escapando desta concepção de saber, seja entendido como "intuição". "Nenhum dos outros saberes contemporâneos expressou melhor e mais profundamente a falência do sujeito da modernidade com suas pretensões de autonomia, reflexividade e autocentramento" (Figueiredo, 2004, p. 42). Sem desconhecer diferenças doutrinárias, em psicanálise há um trânsito entre 0 fenomenal e o metafenomenal. Em outros termos, entre o manifesto e o latente; entre o que se dá a ver/escutar/experienciar e o que resiste; entre a representação e outros sentidos; entre as identidades e seus subterrâneos; entre o "plano do significado" e o "plano das forças". Enfim, entre o discurso clínico e o discurso metapsicológico.

O conceito pilar de "inconsciente", como proposto por Freud, inviabiliza especialmente a manutenção de ilusões a respeito de individualidade, autonomia e consciência. Antes de tudo porque este conceito propõe que o sujeito fundamenta-se na dependência simbólica do desejo do Outro. Daí que haveria, na análise do sintoma, o não dito do discurso dos sujeitos, mas também o não dito dos enunciados sociais. É por esta razão que haveria, por exemplo, várias formas de investigar fenômenos sociais, respeitando os fundamentos éticos e teóricos da psicanálise, "contribuindo para a elucidação de sua eficácia no processo de alienação do sujeito e apontando os laços que possibilitem a sua inclusão como sujeitos do desejo" (Rosa, 2004, p. 340).

Conforme a proposta da psicanálise, no sintoma não há organismo doente, mas uma expressão do sofrimento na relação com o outro: conflitos pessoais, familiares, sociopolíticos e libidinais. "Assim, falar de sujeito é falar de uma concepção ético-política, e não de uma faceta do indivíduo recortado em bio/psico/social, sujeito produto e produtor da rede simbólica que caracteriza o que chamamos o social e o político" (Rosa \& Domingues, 2010, p. 182). o sujeito psicanalítico constitui-se pelo universo simbólico, e ao mesmo tempo o constitui. É dessa forma que ele não é uma entidade de caráter intrasubjetivo ou extrasubjetivo porque ela não faz tal distinção. A subjetividade só é pensada, pela psicanálise, a partir de suas relações com o social.

Sobre a contraposição feita pela psicanálise ao método científico pautado no cogito cartesiano, por sua vez, é suficiente dizer que ela questiona a noção de que o eu existe onde pensa. Em outras palavras, indaga o eu que, julgando conhecer a realidade, não se interroga, e que adquire concretude e toma suas figurações como verdades, imaginárias no mais das vezes.

De qualquer modo, é imprescindível ressalvar que não é exclusividade da psicanálise reger-se por outra lógica que 


\section{H. INTERACÃO EM 1. PSICOLOGIA}

não a da racionalidade cartesiana. Isto se dá em outros campos de saber que ousaram transgredir os ideais da modernidade. Esse não-dito dos discursos sociais, aquilo que é velado pelos discursos sociais, já foi apontado, por exemplo, por Marx.

\section{PSICANÁLISE NA UNIVERSIDADE}

Mostra-se por fim sempre necessário indagar a respeito das possibilidades da pesquisa em psicanálise na universidade. Se a psicanálise poderia interessar a diversos saberes, isto não exime ninguém (talvez, aliás, exija) de demarcar em que se constitui o método de pesquisa psicanalítica. Até mesmo para, como convidamos no início deste artigo, considerar os eventuais benefícios que a psicanálise teria nesta relação com a universidade: explicitar as características de uma pesquisa psicanalítica.

A pesquisa psicanalítica é dirigida à dinâmica psíquica (hipoteticamente inacessível à observação, dela temos acesso apenas a suas manifestações) subjacente ao fenômeno observado. Daí que as respostas do sujeito, independentemente da técnica utilizada, são inverificáveis por estarem subordinadas ao universo fantasmático (conteúdos recalcados relativos à história das escolhas de objeto, das pulsões, caminhos do desejo, etc.). "Por mais que o sujeito se esforce para responder 'objetivamente', os recalcamentos presentes desde o início de sua vida impedem o acesso aos cenários fantasmáticos que alicerçam aquilo que ele está nos comunicando" (Rosa \& Domingues, 2010, p. 185).

Vale ainda mencionar que a pesquisa psicanalítica se diferencia das estratégias metodológicas das abordagens quantitativas e qualitativas, seja porque não objetiva estabelecer inferências generalizadoras (nem mesmo para a amostra), seja porque suas estratégias de análise de resultados não trabalham com o signo, mas com o significante (Iribarry, 2003). Produz-se pesquisa psicanalítica a partir das dimensões do enunciado e da enunciação do discurso, "interceptando a transmissão de dogmas e de idealizações, mediante o conhecimento de uma série de contextos e histórias, acrescido de articulações fora da história oficial" (Rosa \& Domingues, 2010, p. 182).

A particularidade da pesquisa psicanalítica recairia em termos de objetivo - influenciar a posição tomada por pesquisadores em relação aos sentidos presentes no texto apresentado - e de análise de dados, que seriam os significantes. Esta pesquisa pode ser descrita da seguinte maneira:

A experiência com os dados é transformada em texto que identifica e realça marcas no discurso, posições, efeitos de sentido. A escrita do caso vai além de uma apreensão circunstancial e momentânea do observado, pois envolve uma construção, a construção do caso metodológico, que transforma os registros daquilo que se apresenta como enigma em um relato, uma narrativa, uma experimentação e teorização de um campo (Rosa \& Domingues, 2010, p. 186).

É precisamente o estatuto atribuído ao "caso" que permite não apenas alcançar o objetivo da pesquisa psicanalítica e aplicar a metodologia a ela própria, mas também caracterizála como pesquisa psicanalítica. Toda investigação psicanalítica é qualitativa justamente por operar em profundidade com casos específicos, mas compartilhando-o com o universal, e como tal ganhando o caso um valor "exemplar" (Mezan, 2002). Seria a partir do contato profundo com a singularidade que se acessa tanto o que é único/ específico, como o que compartilha/o que é universal, geral.

A pesquisa psicanalítica de fenômenos sociais e políticos, aqui já citada por bem explicitar algumas características das pesquisas psicanalíticas, permite-nos discutir neste momento outro aspecto destas: a relação com outras ciências humanas. Neste caso, ela é fundamental, de forma a compartilhar minimamente os conhecimentos a respeito das condições que levaram a tais fenômenos. Quanto à delimitação da parte do campo que compete à psicanálise, sua pretensão não seria de hegemonia, mas, bem mais modesta, esclarecer uma parcela de seus aspectos, incidindo sobre o que escapa à análise realizada por outros campos: a dimensão inconsciente das práticas sociais (Rosa \& Domingues, 2010).

Sobre pesquisas que pretendem pôr em diálogo mais de uma área de conhecimento, e como alternativa à pluri, multi, inter ou transdisciplinaridade, Mijolla-Mellor (2004, como citado em Aguiar, 2006) propõe o que ela chama "interações da psicanálise". Diversamente de "aplicação", mais usado nos primeiros tempos da psicanálise (no futuro, difamado além do necessário pelos psicanalistas lacanianos, e mais recentemente retomado sem maiores pruridos), "interação" sublinha o fato de "que, antes de interessar os outros campos do saber ou da cultura, a própria psicanálise está interessada nesses campos, na medida em que eles são parte constitutiva dela própria" (Aguiar, 2006, p. 126). É que seu fundador tinha interesse genuíno por várias disciplinas, a partir das quais construiu a sua própria.

As interações da psicanálise são, aliás, uma das fontes de formação daquele que escuta, junto com sua própria análise e textos clínicos ou teóricos. É também da precisão e, ao mesmo tempo, da flexibilização que se faria o saber analítico e seu método, ao compará-lo e confrontá-lo com outros campos. As pesquisas sobre e em psicanálise sairiam 


\section{N"INTERACÃO EM ESTICOLOGIA}

enriquecidas com a integração ao campo das ciências humanas.

Tais interações seriam assim a confrontação dos discursos de diferentes disciplinas a respeito de determinado objeto de estudo, de modo que se destaquem suas especificidades. 0 objetivo não seria chegar a uma unidade dialógica, que, para Mijolla-Mellor (2004, como citado em Aguiar, 2006), é ilusória, mas justamente explicitar as especificidades de cada disciplina, incluindo as oposições entre elas, muitas vezes invisíveis por aparentes semelhanças. Seu objetivo também seria precisar os métodos utilizados por cada disciplina, para o que se emprestaria mutuamente os modelos das disciplinas e se importaria e exportaria conceitos das disciplinas envolvidas.

Por fim, o método da pesquisa psicanalítica não inova quanto à escolha dos sujeitos ou participantes, nem quanto à coleta de dados ou instrumentos e materiais utilizados. Sua novidade seriam os dispositivos metodológicos de análise de dados, nos quais se considera o autor como primeiro e principal participante, ainda que conte em alguns casos com colaboradores (os nomeados "participantes" da pesquisa).

Algumas formas de obtenção de dados: 1) à produção textual dos colaboradores sobre a temática; 2) entrevistas gravadas em áudio e/ou vídeo; 3) fragmentos ou versões integrais de sessões clínicas transcritas; 4) histórias clínicas, biografias e autobiografias literárias; 5) obras de arte (cinema, pintura, fotografia, escultura, literatura, etc.) e 6) material clínico propriamente dito (Iribarry, 2003).

\section{CONSIDERAÇÕES FINAIS}

A discussão sobre a pesquisa psicanalítica mostra-se uma oportunidade não apenas de justificar a possibilidade de diálogo com a universidade, mas principalmente de elucidar alguns conceitos psicanalíticos fundamentais. Neste sentido, pensar nas relações entre psicanálise e universidade é enriquecedor para a disciplina freudiana, dentre outras coisas, porque uma ocasião por excelência de explicitar a outros campos do saber (particularmente os de fundamentos na modernidade) algumas de suas concepções fundamentais.

A primeira delas é a caracterização contemporânea das ciências humanas. O percurso histórico das discussões de Freud a propósito das ciências discorre sobre o que definia, em sua época, as ciências naturais e as do espírito. Ele situa sua descoberta no campo das ciências do inanimado conforme a definição que lhe são próprias; contudo, se consideramos o que hoje define as ciências humanas, podemos utilizar os mesmos argumentos do pai da psicanálise para justificar que hoje o campo por ele descoberto é próprio dos saberes da humanidade.

Um dos aspectos que aproximava a psicanálise das ciências naturais, e hoje a aproxima das ciências humanas, é a busca das causas (tanto no tratamento como na pesquisa). Outro aspecto é a própria natureza de seu objeto (as produções inconscientes), que exige métodos atualmente inerentes às ciências humanas. Neste sentido, as compreensões da psicanálise sobre veracidade, indução, dedução, escolha de procedimentos, definição de problemas, estabelecimento e verificação de hipóteses são as de outras ciências humanas.

As pesquisas psicanalíticas sobre a interface psiquesociedade demonstram, por excelência, outra característica da pesquisa em psicanálise: que ela não se dá apenas a partir da prática analítica. Isto porque o inconsciente encontrase em todo lugar, basta alguém que o escute. As mesmas forças que "animam toda e qualquer produção mental, individual ou coletiva, podem ser detectadas não apenas na situação clínica, mas ainda nas produções secundarizadas" (Mezan, 1994, p. 67). A propósito, o inconsciente e suas produções, vale repetir, é o objeto da pesquisa psicanalítica. Não é por outro motivo que em toda pesquisa na qual a psicanálise dialoga com outros campos de saber (por exemplo, quando aborda a interface psiquesociedade), ela limita-se a falar do inconsciente.

A pesquisa em psicanálise é, talvez acima de tudo, uma transgressão do ideal moderno de consciência. Daí a importância de especificar seu objeto (o inconsciente) e precisar seus métodos. Sobre o método, é o tratamento clínico dos dados que define uma pesquisa psicanalítica, e isto se dá por excelência no ato da escrita: "Na universidade, em particular, a aposta encontra-se, no limite, na transposição do método interpretativo [próprio da psicanálise] para o domínio da leitura de textos" (Aguiar, 2006, p. 114). A pesquisa psicanalítica não inova em termos de escolha dos sujeitos, coleta de dados, instrumentos e materiais, mas na análise dos dados.

Além disto, as pesquisas a respeito da interface psiquesociedade revelam significativamente a concepção de sujeito para a psicanálise: constituinte do social e por ele constituído. Então, esta é uma das maneiras com que a psicanálise transgride o ideal moderno de individualidade e autonomia. Não é por outra razão que, na pesquisa em psicanálise, o pesquisador é considerado parte dos dados. Os dados não existem previamente, mas apenas após a ação de interpretação.

Quanto à prática de pesquisa em psicanálise na universidade, portanto, inicialmente não há a pretensão de verificabilidade (pelo fato de que o inconsciente não é 


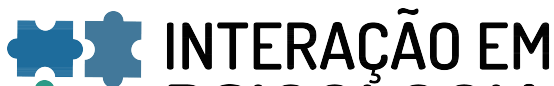 ET PSICOLOGIA}

acessível, mas apenas manifesto em suas formações) e generalizações. Interessa o trabalho com significantes, para o que são úteis os casos específicos, que adquirem o estatuto de exemplaridade.

O método psicanalítico de pesquisa psicanalítica é uma maneira por excelência de conhecermos o método psicanalítico, que integra teoria, prática e pesquisa. É por isto que, ao falar de pesquisa em psicanálise, recorre-se inegavelmente à prática psicanalítica, que é um método de investigação para além de uma teoria.

\section{DECLARAÇÃO DA CONTRIBUIÇÃO DOS AUTORES}

M.M.G. contribuiu para a conceitualização e investigação do artigo; M.M.G. e F.A. fizeram a redação inicial do artigo (rascunho) e M.M.G. e F.A. são os responsáveis pela redação final (revisão e edição).

\section{DECLARAÇÃO DE CONFLITOS DE INTERESSE}

Os autores declaram que não há conflitos de interesse no manuscrito submetido.

\section{FINANCIAMENTO}

Declaramos que não recebemos qualquer financiamento, incluindo de agências de fomento.

\section{REFERÊNCIAS}

Aguiar, F. (2006). Questões epistemológicas e metodológicas em Psicanálise. Jornal de Psicanálise, 39(70), 105-131.

Bianco, A. C. L. (2003). Sobre as bases dos procedimentos investigativos em Psicanálise. Psico-USF, 8(2), 115-123. http://dx.doi.org/10.1590/S1413-82712003000200003

Birman, J. (1994). A clínica na pesquisa psicanalítica. Em Atas do $2^{\circ}$ encontro de pesquisa acadêmica em Psicanálise: Psicanálise e universidade (pp. 7-38). São Paulo: PUC-SP.

Couto, L. F. S. (1996). A pesquisa em psicanálise entre a ciência normal e a revolução científica. Em Couto, L.F.S. (Org.). Pesquisa em Psicanálise, 1(16), 141-151.

Dreher, A. U. (2008). Pluralismo na teoria e na pesquisa: e agora? Revista Brasileira de Psicanálise, 42(2), 131-153.

Figueiredo, L. C. M. (2004). Revisitando as psicologias: da epistemologia à ética das práticas e discursos psicológicos. Rio de Janeiro: Vozes.
Freud, S. (2016). Análise fragmentária de uma histeria (o caso "Dora"). Em Freud, S. Três ensaios sobre sexualidade, análise fragmentária de uma histeria (o caso "Dora") e outros textos (P. C. de Souza, Trad., pp 173-309). São Paulo: Companhia das Letras. (Trabalho original publicado em 1905).

Freud, S. (2010). Recomendações ao médico que pratica a psicanálise. Em Freud, S. Observações psicanalíticas sobre um caso de paranoia relatado em autobiografia ("o caso Schereber"), artigos sobre técnica e outros textos (P. C. de Souza, Trad., pp. 147-162). São Paulo: Companhia das Letras. (Trabalho original publicado em 1912).

Freud, S. (1996). Faut-il enseigner la psychanalyse à l'université? In EFuvres complètes, v. XVIII. Paris: PUF. (Trabalho original publicado em 1919).

Freud S. (2011). Psicologia das massas e análise do eu. Em Freud, S. Psicologia das massas e análise do eu e outros textos (P. C. de Souza, Trad., pp. 9-100). São Paulo: Companhia das Letras. (Trabalho original publicado em 1921).

Garcia, C. \& Silva, M .E. L. (1994). Painel: natureza e delimitação da pesquisa acadêmica em psicanálise. Atas do $2^{\circ}$ encontro de pesquisa acadêmica em Psicanálise: Psicanálise e universidade (pp. 39-50). São Paulo: PUC-SP.

Garcia-Roza, L. A. (1994). A pesquisa de tipo teórico. Atas do $1^{\text {a }}$ encontro de pesquisa acadêmica em Psicanálise: Psicanálise e universidade (pp. 9-32). São Paulo: PUC-SP.

Herrmann, F. (1994). Problemas na orientação de teses de psicanálise. Atas do $1^{\circ}$ encontro de pesquisa acadêmica em Psicanálise: Psicanálise e universidade (pp. 33-50). São Paulo: PUC-SP.

Herrmann, F. (2004). Pesquisa psicanalítica. Ciência e Cultura, 56(4), 25-28.

Iribarry, I. N. (2003). O que é pesquisa psicanalítica?. Ágora: Estudos em Teoria Psicanalítica, 6(1), 115-138. http:// dx.doi.org/10.1590/S1516-14982003000100007

Kupfer, M. C. M. \& Voltolini, R. (2005). Uso de indicadores em pesquisas de orientação psicanalítica: um debate conceitual. Psicologia: Teoria e Pesquisa, 21(3), 359-364. http://dx.doi.org/10.1590/S0102-37722005000300013

Matos, R. P. C., Carvalho Filho, J. G. T. de, Castro, J. E. de, Dias, M. das G. V. L., Calzavara, M. G. P., \& Chaves, W. C. (2008). Articulações entre conceitos fundamentais da Psicanálise, sua clínica e a pesquisa na universidade. Interação em Psicologia, 12(1), 133-140. http://dx.doi.org/ 10.5380/psi.v12i1.7853

Mezan, R. (1993). A sombra de Don Juan e outros ensaios. São Paulo: Brasiliense.

Mezan, R. (1994). Pesquisa teórica em Psicanálise. Atas do $2^{\circ}$ encontro de pesquisa acadêmica e universidade: Psicanálise e universidade (pp. 51-75). São Paulo: PUC-SP. 


\section{N"INTERACÃO EM ESTICOLOGIA}

Mezan, R. (1998). Escrever a clínica. São Paulo: Casa do Psicólogo.

Mezan, R. (2002). Interfaces da psicanálise. São Paulo: Companhia das Letras.

Mezan, R. (2007). Que tipo de ciência é, afınal, a Psicanálise?. Natureza Humana, 9(2), 319-359.

Rosa, M. D. (2004). A pesquisa psicanalítica dos fenômenos sociais e políticos: metodologia e fundamentação teórica. Revista Mal-Estar e Subjetividade, 4(2).

Rosa, M. D. \& Domingues, E. (2010). O método na pesquisa psicanalítica de fenômenos sociais e políticos: A utilização da entrevista e da observação. Psicologia \& Sociedade, 22(1), 180-188. http://dx.doi.org/10.1590/ S0102-71822010000100021

Silva, J. F. R. da, Yazigi, L., \& Fiore, M. L. de M. (2008). Psicanálise e universidade: A interface possível por meio da pesquisa psicanalítica clínica. Alice quebra-vidros. Revista Brasileira de Psiquiatria, 30(2), 152-155. http:// dx.doi.org/10.1590/S1516-44462008005000011

Submetido em 02/04/2016

Primeira decisão editorial em 28/04/2017

Aceito em 23/10/2017

1 Para Freud (1912/2010), "um dos méritos" de sua disciplina "é o fato de nela coincidirem pesquisa e tratamento" - feita a ressalva, fundamental, de que o trabalho científico pressupõe, em particular, "compor a estrutura [do caso], prever seu prosseguimento, de quando em quando registrar o estado em que se acham como exigiria o interesse científico" (p. 153-154). Nesse sentido, a seu ver, após certo ponto, a "técnica" exigida pelo trabalho científico opõe-se àquela requerida pelo tratamento (Freud, 1912/2010, p.153) 